\title{
НОВЫЕ МИНЕРАЛЫ
}

DOI: $10.30695 / \mathrm{zrmo} / 2019.1482 .04$

Н. В. ЩИПАЛКИНА, *** д. чЛ. И. В. ПЕКОВ,**** Д. А. КСЕНОФОНТОВ,* д. чл. Н. В. ЧУКАНОВ,**** д. чл. Д. И. БЕЛАКОВСКИЙ,*****

Н. Н. КОШЛЯКОВА*

\section{ДАЛЬНЕГОРСКИТ $\mathrm{Ca}_{5} \mathrm{Mn}\left(\mathrm{Si}_{3} \mathrm{O}_{9}\right)_{2}-$ НОВЫЙ ПИРОКСЕНОИД СО СТРУКТУРОЙ БУСТАМИТА, ПОРОДООБРАЗУЮЩИЙ МИНЕРАЛ ИЗВЕСТКОВЫХ СКАРНОВ ДАЛЬНЕГОРСКОГО БОРОСИЛИКАТНОГО МЕСТОРОЖДЕНИЯ (ПРИМОРСКИЙ КРАЙ, РОССИЯ)}

\author{
* Московский государственный университет, геологический факультет, \\ 119991, Москва, Воробьевы горы; \\ e-mail: estel58@yandex.ru, igorpekov@mail.ru \\ ** ФНИЦ «Кристаллография и фотоника» им. А. В. Шубникова РАН, Москва \\ *** Институт геохимии и аналитической химии (ГЕОХИ) РАН, \\ 119991, Москва, ул. Косыгина, 19 \\ **** Институт проблем химической физики РАН, \\ 142432, Московская обл., Черноголовка \\ ***** Минералогический музей им. А. Е. Ферсмана РАН, \\ 115162, Москва, Ленинский пр., 18(2)
}

Новый пироксеноид дальнегорскит с кристаллохимической формулой $\mathrm{Ca}_{2} \mathrm{Ca}_{2} \mathrm{MnCa}\left(\mathrm{Si}_{3} \mathrm{O}_{9}\right)_{2}$ и упрощенной формулой $\mathrm{Ca}_{5} \mathrm{Mn}\left(\mathrm{Si}_{3} \mathrm{O}_{9}\right)_{2}$ является породообразующим минералом в бороносных известковых скарнах Дальнегорского боросиликатного месторождения (Дальнегорск, Приморский край, Россия). Он принадлежит к структурному типу бустамита и образует непрерывный ряд с изоструктурным ему ферробустамитом $\mathrm{Ca}_{2} \mathrm{Ca}_{2} \mathrm{FeCa}\left[\mathrm{Si}_{3} \mathrm{O}_{9}\right]_{2}$. Эти пироксеноиды слагают тонколучистые полосчатые агрегаты бежевого, розовато-белого и молочно-белого цвета, ассоциируя с геденбергитом, датолитом, андрадитом, галенитом, сфалеритом, пирротином. $D_{\text {изм. }}=3.02(2), D_{\text {выч. }}=3.035 \Gamma^{\circ} \mathrm{cm}^{-3}$. Дальнегорскит оптически двуосный, отрицательный, $\alpha=1.640(3), \beta=1.647(3), \gamma=1.650(3)^{\circ}, 2 V_{\text {изм. }}=75(10)^{\circ}$. Средний химический состав голотипа (электронно-зондовые данные): $\mathrm{MgO} 0.23, \mathrm{CaO} 40.02, \mathrm{MnO} 5.02, \mathrm{FeO} 3.64, \mathrm{SiO}_{2} 50.65$, сумма 99.56 мас.\%. Эмпирическая формула, рассчитанная на 18 атомов О: $\mathrm{Ca}_{5.03} \mathrm{Mn}_{0.51} \mathrm{Fe}_{0.36} \mathrm{Mg}_{0.04} \mathrm{Si}_{6.03} \mathrm{O}_{18}$. Кристаллическая структура дальнегорскита уточнена по порошковым рентгенодифракционным данным методом Ритвельда, $R_{\mathrm{p}}=0.0345, R_{w p}=0.0444, R_{1}=0.0790, w R_{2}=0.0802$. Минерал триклинный, $P-1, a=7.2588(11), b=7.8574(15), c=7.8765(6) \AA, \alpha=88.550(15), \beta=62.582(15)$, $\gamma=76.621(6)^{\circ}, V=386.23(11) \AA^{3}, Z=1$. Дальнегорскит четко отличается от родственного ему волластонита по инфракрасному спектру. Волновые числа сильных линий в характеристической области валентных колебаний $\mathrm{Si}-\mathrm{O}$ в ИК-спектре дальнегорскита $\left(\mathrm{cm}^{-1}\right)$ : 905, 937, 1025, 1070. Голотипный образец находится в Минералогическом музее им. А. Е. Ферсмана РАН в Москве (№ 96201).

Ключевые слова: дальнегорскит, ферробустамит, бустамит, волластонит, пироксеноид, новый минерал, кристаллическая структура, метод Ритвельда, ИК-спектроскопия, известковый скарн, борное месторождение, Дальнегорск, Приморский край. 


\author{
N. V. SHCHIPALKINA,*,** I. V. PEKOV,**** D. A. KSENOFONTOV,* \\ N. V. CHUKANOV, ${ }^{* * * *}$ D. I. BELAKOVSKIY, ,**** N. N. KOSHLYAKOVA.* \\ DALNEGORSKITE, $\mathrm{Ca}_{5} \mathrm{Mn}\left(\mathrm{Si}_{3} \mathrm{O}_{9}\right)_{2}$, A NEW PYROXENOID OF THE BUSTAMITE \\ STRUCTURE TYPE, A ROCK-FORMING MINERAL OF CALCIC SKARNS \\ OF THE DALNEGORSKOE BORON DEPOSIT (PRIMORSKIY KRAY, RUSSIA) \\ * Moscow State University, Moscow, Russia \\ ** Federal scientific research center «Crystallography and photonica» RAS, Moscow, Russia \\ *** Institute of Geochemistry and Analytical Chemistry RAS, Moscow, Russia \\ **** Institute of Problems of Chtmical Physics RAS, Moscow Region, Chernogolovka, Russia \\ ***** A. E. Fersman Mineralogical Museum RAS, Moscow, Russia
}

\begin{abstract}
Dalnegorskite - the new pyroxenoid with the crystal-chemical formula $\mathrm{Ca}_{2} \mathrm{Ca}_{2} \mathrm{MnCa}\left(\mathrm{Si}_{3} \mathrm{O}_{9}\right)_{2}$, and the simplified formula $\mathrm{Ca}_{5} \mathrm{Mn}\left(\mathrm{Si}_{3} \mathrm{O}_{9}\right)_{2}$, is a rock-forming mineral in the boron-bearing calcareous skarns of the Dalnegorskoe boron-silicate deposit (Dalnegorsk, Primorsky Krai, Russia). It belongs to the structural type of bustamite and forms a continuous solid-solution series with the isostructural mineral ferrobustamite $\mathrm{Ca}_{2} \mathrm{Ca}_{2} \mathrm{FeCa}\left[\mathrm{Si}_{3} \mathrm{O}_{9}\right]_{2}$. These pyroxenoids form thinly-radiated banded beige, pinkish-white and milky-white aggregates typically consisting of split thin acicular to fiber-like individuals and are associated with hedenbergite, datolite, andradite, galena, sphalerite, and pyrrhotite. $D_{\text {meas. }}=3.02(2), D_{\text {calc. }}=3.035 \mathrm{~g} \cdot \mathrm{cm}^{-3}$. Dalnegorskite is optically biaxial, negative, $\alpha=1.640$ (3), $\beta=1.647(3), \gamma=1.650(3)^{\circ}, 2 V_{\text {meas. }}=75(10)^{\circ}$. The average chemical composition of the holotype (electron microprobe data) is: $\mathrm{MgO} 0.23, \mathrm{CaO} 40.02, \mathrm{MnO} 5.02, \mathrm{FeO} 3.64, \mathrm{SiO}_{2} 50.65$, total 99.56 wt.\%. The empirical formula calculated on $18 \mathrm{O}$ atoms is $\mathrm{Ca}_{5.03} \mathrm{Mn}_{0.51} \mathrm{Fe}_{0.36} \mathrm{Mg}_{0.04} \mathrm{Si}_{6.03} \mathrm{O}_{18}$. The crystal structure of the new mineral was refined by powder X-ray diffraction data using the Rietveld method, $R_{\mathrm{p}}=0.0345, R_{w p}=0.0444, R_{1}=0.0790, w R_{2}=0.0802$. Dalnegorskite is triclinic, $P-1$, $a=7.2588(11), b=7.8574(15), c=7.8765(6) \AA, \alpha=88.550(15), \beta=62.582(15), \gamma=76.621(6)^{\circ}$, $V=386.23(11) \AA^{3}, Z=1$. Dalnegorskite is distinctly different from the related mineral wollastonite in the infrared spectrum. The wave-numbers of maxima of strong bands in the characteristic region of $\mathrm{Si}-\mathrm{O}$ stretching vibrations in the IR spectrum of dalnegorskite are $\left(\mathrm{cm}^{-1}\right): 905,937,1025,1070$. The type specimen of dalnegorskite is deposited in the collection of the Fersman Mineralogical Museum of the Russian Academy of Sciences, Moscow, Russia (No. 96201).

Keywords: dalnegorskite, ferrobustamite, bustamite, wollastonite, pyroxenoid, new mineral, crystal structure, Rietveld method, IR spectroscopy, calcic skarn, boron deposit, Dalnegorsk, Primorsky Krai.
\end{abstract}

\title{
ВВЕДЕНИЕ
}

Описываемый в настоящей статье новый минерал дальнегорскит с кристаллохимической формулой $\mathrm{Ca}_{2} \mathrm{Ca}_{2} \mathrm{MnCa}\left(\mathrm{Si}_{3} \mathrm{O}_{9}\right)_{2}$ и упрощенной формулой $\mathrm{Ca}_{5} \mathrm{Mn}\left(\mathrm{Si}_{3} \mathrm{O}_{9}\right)_{2}$ является представителем структурного типа бустамита, который объединяет пироксеноиды с общей формулой $M 1_{2} M 2_{2} M_{3} M_{4}\left(\mathrm{Si}_{3} \mathrm{O}_{9}\right)_{2}$, где видообразующие катионы $M=\mathrm{Ca}, \mathrm{Mn}^{2+}, \mathrm{Fe}^{2+}$. От других представителей этого структурного типа - собственно бустамита $\mathrm{Ca}_{2} \mathrm{Mn}_{2} \mathrm{MnCa}\left(\mathrm{Si}_{3} \mathrm{O}_{9}\right)_{2}$ (Peacor, Buerger, 1962) ферробустамита $\mathrm{Ca}_{2} \mathrm{Ca}_{2} \mathrm{FeCa}\left(\mathrm{Si}_{3} \mathrm{O}_{9}\right)_{2}$ (Rapoport, Burnham, 1973) и мендигита $\mathrm{Mn}_{2} \mathrm{Mn}_{2} \mathrm{MnCa}\left(\mathrm{Si}_{3} \mathrm{O}_{9}\right)_{2}$ (Чуканов и др., 2015) - он отличается химическим составом и, соответственно, набором видообразующих $M$-катионов, являясь, по сути, аналогом ферробустамита с преобладанием $\mathrm{Mn}$ над Fe в позиции $M 3$.

Дальнегорскит назван по месту находки - Дальнегорскому боросиликатному месторождению, расположенному в городе Дальнегорск в южной части хребта Сихотэ-Алинь в Приморском крае на Дальнем Востоке России. Этот пироксеноид - один из главных породообразующих минералов известковых скарнов и датолитовых руд Дальнегорского месторождения - единственного на сегодня разрабатываемого месторождения бора в России.

История изучения этого минерала из Дальнегорского месторождения довольно интересна. Впервые он был описан как «волластонит» или « $\mathrm{Mn}, \mathrm{Fe}-$ вол- 
ластонит» в 40-х гг. XX в. Заметим, что волластонит долгое время рассматривался как твердый раствор $\mathrm{Ca}_{3} \mathrm{Si}_{3} \mathrm{O}_{9}-\mathrm{Fe}_{3} \mathrm{Si}_{3} \mathrm{O}_{9}-\mathrm{Mn}_{3} \mathrm{Si}_{3} \mathrm{O}_{9}$. Как отмечали авторы работ (Мельницкая, 1967; Куршакова, 1976), предполагаемая Мn- и

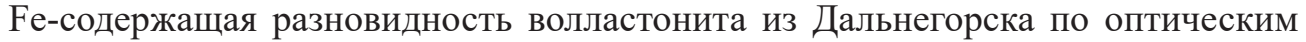
характеристикам и по данным порошковой рентгенографии не может относиться к минералу со структурным типом бустамита. Позже эти представления были пересмотрены. Так, результаты инфракрасной спектроскопии дальнегорского «волластонита», опубликованные В. Т. Казаченко с соавторами (2012), показали, что он близок, скорее, к бустамиту (к которому и отнесен в цитированной работе), чем к волластониту. Отметим, что в образцах изученной нами достаточно представительной коллекции дальнегорских «датолит-волластонитовых» скарнов собственно волластонит установлен не был.

Наше детальное исследование этого минерала, включающее уточнение кристаллической структуры по методу Ритвельда, позволило однозначно установить его принадлежность к структурному типу бустамита. Согласно принятым Международной минералогической ассоциацией (ММА) кристаллохимическим критериям, он представляет собой самостоятельный минеральный вид. По нашей заявке Комиссия по новым минералам, номенклатуре и классификации ММА утвердила его как новый минерал с названием дальнегорскит (IMA N 2018-007). Голотипный материал передан в Минералогический музей им. А. Е. Ферсмана РАН в Москве и находится в систематической коллекции Музея под номером 96201.

\section{УСЛОВИЯ НАХОЖДЕНИЯ И МОРФОЛОГИЯ}

Дальнегорское боросиликатное месторождение было открыто в 1946 г. в ходе работ, проводившихся Государственным научно-исследовательским институтом горно-химического сырья (ГИГХС) Министерства химической промышленности СССР. Оно располагается в юго-восточном крыле Южной антиклинали в пределах Дальнегорского рудного поля (Приморский край, Россия) и приурочено в основном к зоне контакта известняков с биотит-роговообманковыми гранитами. Промышленная борная (датолитовая) минерализация этого месторождения связана с известковыми скарнами, образовавшимися на контакте песчаников и известняков тетюхинской свиты $\left(\mathrm{T}_{3}\right)$. Зона бороносных скарнов мощностью более 500 м прослеживается на протяжении 3.5 км в северо-восточном направлении. Дальнегорскит вместе с визуально неотличимым от него ферробустамитом, с которым он образует непрерывный изоморфный ряд с плавным изменением отношения $\mathrm{Mn}: \mathrm{Fe}$ (см. ниже), является одним из ведущих, а местами и главным минералом бороносных скарнов и связанных с ними более поздних гидротермальных образований. Наблюдаются две текстурные разновидности этих скарнов - сферолитовая и полосчатая. Первая содержит скопления сферических образований пироксеноида ряда дальнегорскит-ферробустамит (ранее описывавшегося как волластонит) и/или геденбергита. Полосчатый рисунок второй разновидности скарнов обусловлен формой поверхности, вдоль которой отлагались минералы: прямолинейные, волнистые или изогнутые трещины в известняках, контакты разных пород (Куршакова, 1976; Moroshkin, Frishman, 2001). Отметим, что фестончатая, полосчатая разновидность таких скарнов известна как красивый рисунчатый поделочный и облицовочный камень. В частности, им инкрусти- 



Рис. 1. Изображения под сканирующим электронным микроскопом в отраженных $(a)$ и вторичных (б) электронах типичных агрегатов дальнегорскита.

Fig. 1. Backscattered-electron $(a)$ and secondary-electron (б) SEM images of typical aggregates of dalnegorskite.

рованы колонны и стены вестибюля станции Петровско-Разумовская Московского метрополитена.

Дальнегорскит образует плотные тонколучистые агрегаты, состоящие из расщепленных тонкоигольчатых до волокнистых кристаллов, как правило не превышающих 2-3 мм в длину и $3-5$ мкм в толщину (рис. 1). Эти агрегаты формируют полосчатые зоны в скарновых телах (рис. 2) и концентрически-полосчатые зоны в своеобразных силикатных сферолитах-«почках» в полостях этих тел. Такая полосчатость обусловлена чередованием зон, сложенных преимущественно пироксеноидами (дальнегорскитом/ферробустамитом), геденбергитом, андрадитом и датолитом. Мощность зон с дальнегорскитом и ферробустамитом, которые преобладают в этих скарновых телах, нередко достигает 5 см. Промежутки между концентрически-зональными, с прослоями
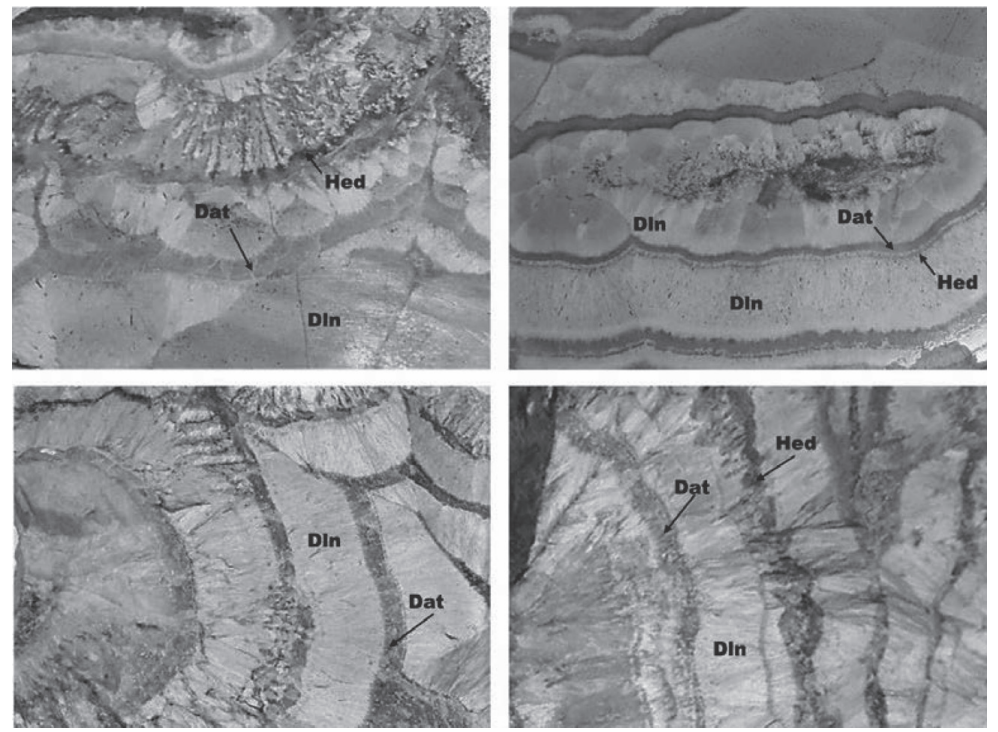

Рис. 2. Типичные агрегаты дальнегорскита (Dln), датолита (Dat) и геденбергита (Hed). Полированные пластины. Ширина поля зрения составляет для каждого рисунка 7 см.

Fig. 2. Typical aggregates consisting of dalnegorskite (Dln), datolite (Dat) and hedenbergite (Hed). Polished sections. Field width is $7 \mathrm{~cm}$ for each photograph. 
датолита и геденбергита, агрегатами дальнегорскита (в том числе в ориентированных друг навстречу другу корках, росших в свободном пространстве трещин и полостей) заполнены геденбергитом, датолитом и кварцем (рис. 2). Среди акцессорных рудных минералов здесь наиболее распространены галенит и сфалерит, встречаются пирротин, кобальтин, пирит и теннантит. Более подробные сведения об акцессорной минерализации в этих скарнах можно найти в статье В. Т. Казаченко с соавторами (2012).

\section{ФИЗИЧЕСКИЕ СВОЙСТВА И ОПТИЧЕСКИЕ ХАРАКТЕРИСТИКИ}

Цвет агрегатов дальнегорскита варьирует от светло-бежевого, розоватоили желтовато-белого до молочно-белого. На полированных срезах отчетливо проявляется шелковистый блеск тонколучистых агрегатов, а на сколе блеск минерала тусклый стеклянный. Мелкие индивиды прозрачны, тогда как агрегаты лишь слабо просвечивают в тонких сколах. Дальнегорскит не флюоресцирует в ультрафиолетовых лучах. Отдельные мелкие иглы минерала хрупкие, в то время как их агрегаты весьма вязкие, с трудом раскалываются молотком. Твердость дальнегорскита по шкале Мооса 6. Совершенная спайность у его игл наблюдалась под микроскопом; по аналогии с бустамитом мы считаем, что плоскость этой спайности параллельна (100). Плотность, измеренная методом гидростатического взвешивания, близка к вычисленной на основе эмпирической формулы: их значения составляют 3.02(2) и 3.035 г/ $\mathrm{cm}^{3}$ соответственно.

В проходящем свете (589 нм) новый минерал оптически двуосный отрицательный, $\alpha=1.640(3), \beta=1.647(3), \gamma=1.650(3)^{\circ}, 2 V_{\text {изм. }}=75(10)^{\circ}, 2 V_{\text {выч. }}=66^{\circ}$. Под микроскопом дальнегорскит бесцветный, плеохроизма не наблюдается.

\section{ИНФРАКРАСНАЯ СПЕКТРОСКОПИЯ}

ИК-спектр поглощения дальнегорскита получен на фурье-спектрометре ALPHA (Bruker Optics) в диапазоне 360-3800 см-1 при разрешающей способности 4 см$^{-1}$ и числе сканирований 16 (рис. 3). Образец для съемки ИК-спектра был подготовлен по стандартной методике таблетирования с $\mathrm{KBr}$.

В ИК-спектре дальнегорскита проявлены полосы $\left(\mathrm{cm}^{-1}, \mathrm{c}\right.$ - сильная полоса, пл - плечо), отвечающие деформационным колебаниям $\mathrm{Si}-\mathrm{O}-\mathrm{Si}$ и валентным колебаниям $M \cdots \mathrm{O}$, где $M=\mathrm{Ca}, \mathrm{Mn}, \mathrm{Fe}(513,505,470 п л, ~ 458 c, 445 п л, ~ 407)$, деформационным колебаниям O- $\mathrm{Si}-\mathrm{O}(693,653,563)$, валентным колебаниям $\mathrm{Si}-\mathrm{O}$ с участием апикальных (немостиковых) атомов кислорода $(937 \mathrm{c}, 905 \mathrm{c})$ и валентным колебаниям $\mathrm{Si}-\mathrm{O}$ фрагмента $\mathrm{Si}-\mathrm{O}$ - $\mathrm{Si}(1077 \mathrm{c}, 1025 \mathrm{c})$. Для сравнения на рис. 3 приведены ИК-спектры бустамита и волластонита- $1 A$. В спектрах всех этих минералов в области частот выше $1100 \mathrm{~cm}^{-1}$ отсутствуют полосы с интенсивностями выше уровня шума, что свидетельствует об отсутствии примесей, содержащих группировки с ковалентными связями $\mathrm{O}-\mathrm{H}, \mathrm{O}-\mathrm{C}$ и $\mathrm{O}-\mathrm{B}$.

Важным диагностическим признаком минералов со структурой бустамита является наличие четырех максимумов поглощения в ИК-диапазоне 900$1100 \mathrm{~cm}^{-1}$, тогда как в ИК-спектре волластонита в этом диапазоне присутствуют шесть сильных полос. Бустамит и изоструктурные с ним минералы отличаются друг от друга по набору полос в области валентных колебаний $M \cdots \mathrm{O}$, т. е. $400-520 \mathrm{~cm}^{-1}$. 


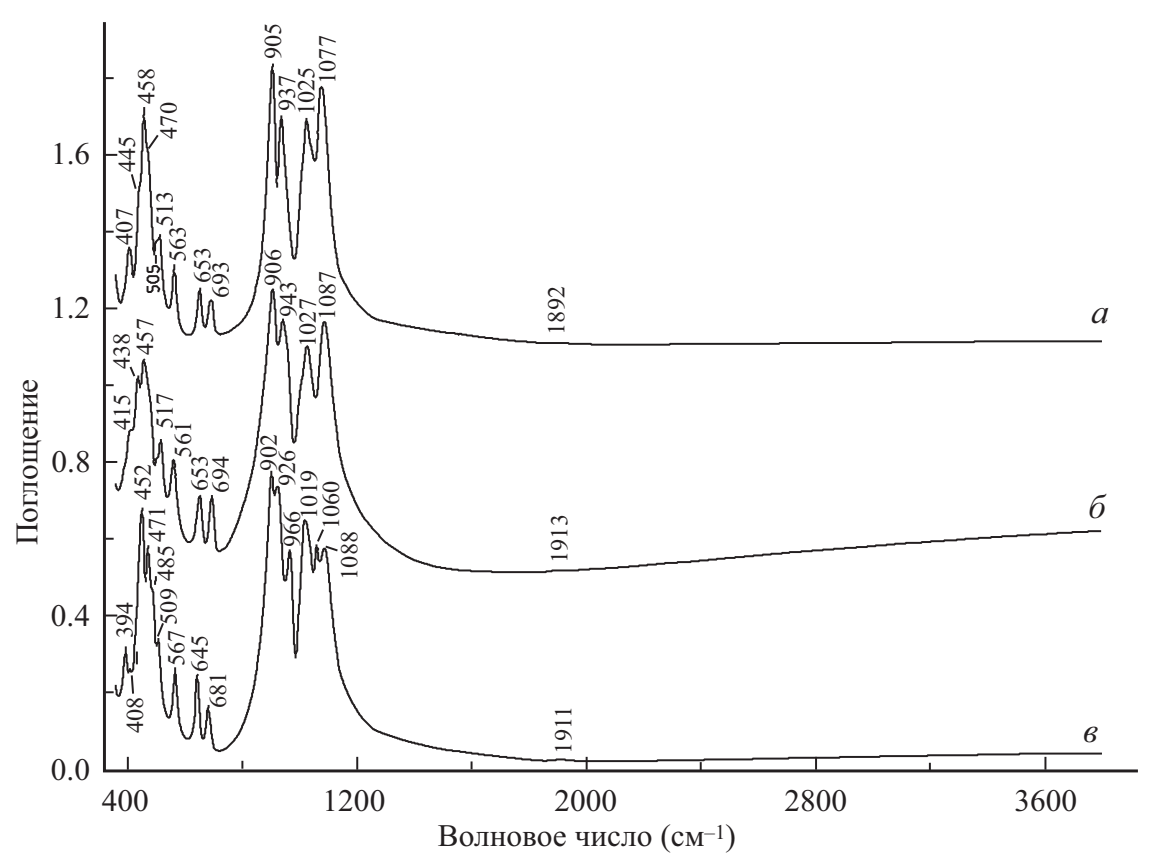

Рис. 3. Инфракрасные спектры дальнегорскита из Дальнегорска $(a)$, бустамита из месторождения Брокен Хилл, Австралия (б) и волластонита- $1 A$ из Акчатау, Казахстан (в).

Fig. 3. Infrared absorption spectra of dalnegorskite from Dalnegorsk $(a)$, bustamite from Broken Hill, New South Wales, Australia (б), and wollastonite-1A from Akchatau, Kazakhstan ( 8 ).

\section{ХИМИЧЕСКИЙ СОСТАВ}

Химический состав нового минерала определен методом электронно-зондового микроанализа. Изучение дальнегорскита проводилось на электронном микроскопе Jeol 6480lv, оснащенном энергодисперсионным спектрометром INCA Energy-350, в Лаборатории локальных методов исследования вещества кафедры петрологии геологического факультета МГУ им. М. В. Ломоносова. Результаты получены при ускоряющем напряжении 20 кВ, силе тока электронного зонда 10 нА и диаметре электронного пучка 100 нм. Определяемыми элементами являлись $\mathrm{Mg}, \mathrm{Si}, \mathrm{Al}, \mathrm{Ca}, \mathrm{Mn}, \mathrm{Fe}$. Для количественного анализа были использованы следующие эталоны: диопсид для $\mathrm{Mg}$, волластонит для Сa, металлический марганец для $\mathrm{Mn}$, гиперстен для $\mathrm{Fe}$ и $\mathrm{Si}$, роговая обманка для Al. Аналитическими для всех элементов были линии $K$-серий. Содержания остальных элементов с атомными номерами выше, чем у кислорода, оказались ниже пределов обнаружения данным методом.

В табл. 1 представлен химический состав типичных образцов минералов ряда дальнегорскит-ферробустамит из Дальнегорского боросиликатного месторождения. Усредненный химический состав голотипного образца дальнегорскита: $\mathrm{MgO} 0.23, \mathrm{CaO} 40.02, \mathrm{MnO} 5.02, \mathrm{FeO} 3.64, \mathrm{SiO}_{2} 50.65$, сумма 99.56 мас. \%. Рассчитанная на 18 атомов О эмпирическая формула, отвечающая этому составу: $\mathrm{Ca}_{5.03} \mathrm{Mn}_{0.51} \mathrm{Fe}_{0.36} \mathrm{Mg}_{0.04} \mathrm{Si}_{6.03} \mathrm{O}_{18}$. Идеализированная формула конечного члена, с учетом структурных данных (см. ниже) $-\mathrm{Ca}_{5} \mathrm{Mn}\left(\mathrm{Si}_{3} \mathrm{O}_{9}\right)_{2}$. 


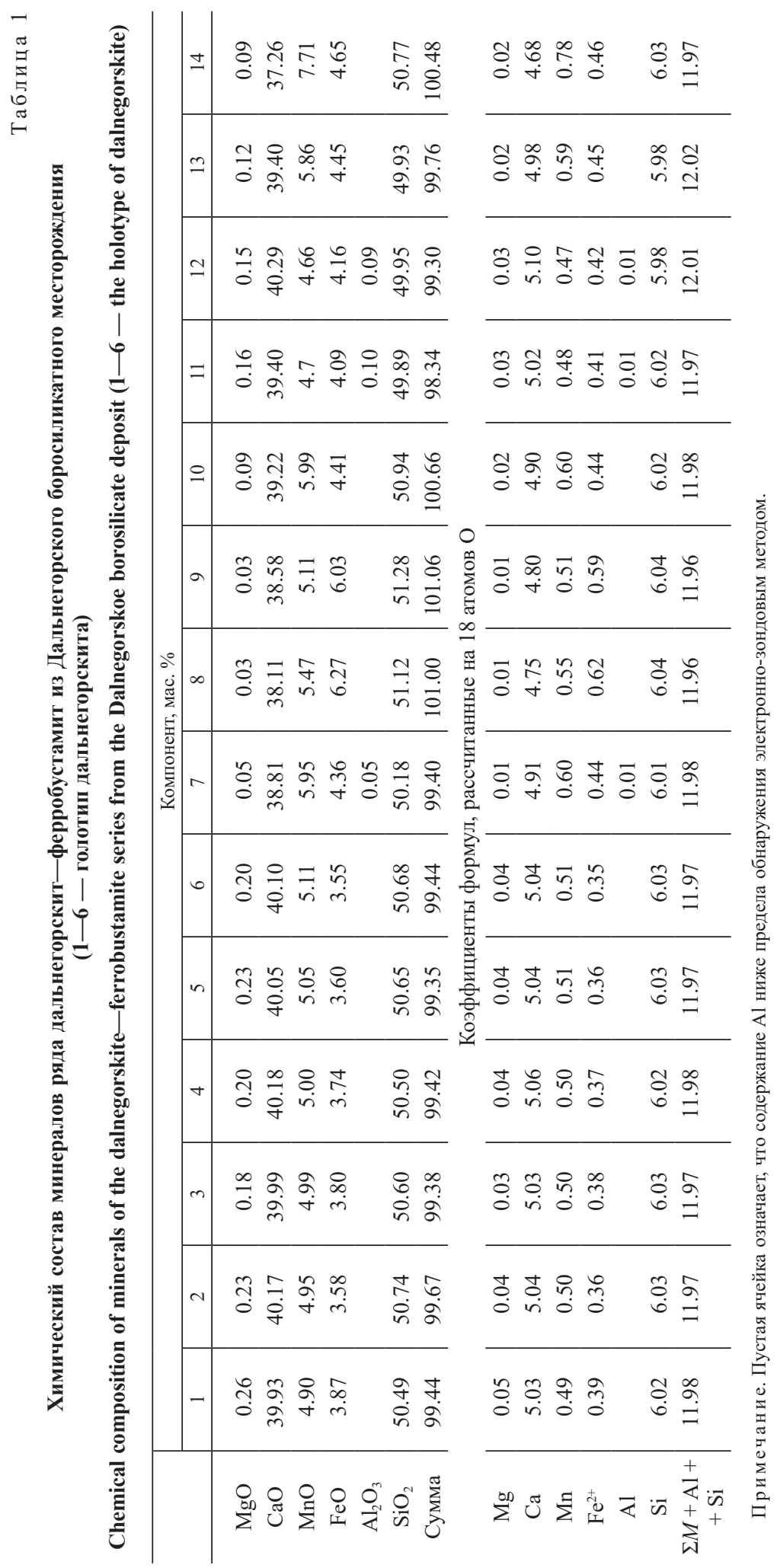




\section{РЕНТГЕНОГРАФИЧЕСКОЕ ИЗУЧЕНИЕ И РЕНТГЕНОСТРУКТУРНЫЙ АНАЛИЗ}

Особенности морфологии дальнегорскита (тонкая расщепленность игольчатых и волокнистых индивидов) сделали невозможным изучение его кристаллической структуры методом монокристального рентгеноструктурного анализа, поэтому для уточнения структуры данного минерала использовался метод Ритвельда.

Рентгенодифракционные данные получены на порошковом дифрактометpe STOE STADI MP с изогнутым Ge(111) монохроматором, обеспечивающим строго монохроматизированное СоК $\alpha_{1}$ излучение $(\lambda=1.78896 \AA)$. Сбор данных происходил при комнатной температуре в режиме поэтапного перекрывания областей сканирования с помощью позиционно-чувствительного линейного детектора, угол захвата которого составлял $5^{\circ}$ по $2 \theta$ с шириной канала $0.02^{\circ}$, в диапазоне $5.00^{\circ}<2 \theta<108.98^{\circ}$. Уточнение структуры проводилось в программе JANA2006 (Petříček et al., 2014). В качестве исходной модели была взята структурная модель бустамита, предложенная в статье (Ohashi, Finger, 1978). Для описания формы дифракционных пиков использована функция pseudo-Voigt. Текстурирование образца по направлению (001) учитывалось с помощью функции March-Dollase.

Рассчитанные по порошковым рентгенодифракционным данным параметры триклинной элементарной ячейки дальнегорскита: $a=7.2588(11)$, $b=7.8574(15), c=7.8765(6) \AA, \alpha=88.550(15), \beta=62.582(15), \gamma=76.621(6)^{\circ}$, $V=386.23(11) \AA^{3}$. Заключительные значения факторов расходимости: $R_{p}=0.0345, R_{w p}=0.0444, R_{1}=0.0790, w R_{2}=0.0802$. Данные рентгенодифракционного эксперимента и результаты уточнения структуры приведены в табл. 2. Уточненные по порошковым данным координаты атомов и межатомные расстояния приведены в табл. 3 и 4 соответственно.

Таблица 2

Кристаллографические характеристики дальнегорскита и результаты уточнения его кристаллической структуры

Crystal data and structure refinement details for dalnegorskite

\begin{tabular}{|c|c|}
\hline Формула & $\mathrm{Ca}_{2} \mathrm{Ca}_{2} \mathrm{MnCa}\left(\mathrm{Si}_{3} \mathrm{O}_{9}\right)_{2}$ \\
\hline Сингония & Триклинная \\
\hline Пространственная группа & $P-1$ \\
\hline$a(\AA)$ & $7.2588(11)$ \\
\hline$b(\AA)$ & $7.8574(15)$ \\
\hline$c(\AA)$ & $7.8765(6)$ \\
\hline$\alpha\left(^{\circ}\right)$ & $88.500(15)$ \\
\hline$\beta\left(^{\circ}\right)$ & $62.582(15)$ \\
\hline$\gamma\left({ }^{\circ}\right)$ & $76.621(6)$ \\
\hline$V\left(\AA^{3}\right)$ & $386.23(11)$ \\
\hline$Z$ & 1 \\
\hline Излучение, $\lambda(\AA)$ & $\mathrm{CoK} \alpha_{1} ; 1.78892$ \\
\hline Температура (K) & 293 \\
\hline Число брэгговских рефлексов & 609 \\
\hline Число уточняемых параметров & 99 \\
\hline Интервал $2 \theta\left(^{\circ}\right)$ & от 5.00 до 108.98 \\
\hline Функция профиля & pseudo-Voigt \\
\hline$G O F$ & 1.34 \\
\hline Заключительные значения $R^{*}$ & $R_{p}=0.0345, R_{w p}=0.0444, R_{1}=0.0790, w R_{2}=0.0802$ \\
\hline
\end{tabular}


Координаты атомов, эквивалентные параметры атомных смещений $\left(U_{\text {eq }}, \AA^{2}\right)$, кратность $(Q)$ и заселенность позиций в структуре дальнегорскита

Atom coordinates, equivalent displacement parameters $\left(U_{\mathrm{eq}}, \AA^{2}\right)$, site multiplicities $(Q)$ and site occupancies for dalnegorskite

\begin{tabular}{c|c|l|l|l|l|l|c}
\hline Позиция & $x / a$ & $y / b$ & $z / c$ & $U_{\text {eq }}$ & $Q$ & $e_{\text {ref }}(\mathrm{pfu})$ & $\begin{array}{c}\text { Заселенность } \\
\text { позиции }\end{array}$ \\
\hline M1 & $-0.788(6)$ & $-0.802(3)$ & $0.762(3)$ & $0.024(8)$ & 2 & 20.01 & $\mathrm{Ca}$ \\
$M 2$ & $-0.306(5)$ & $-0.801(3)$ & $0.746(3)$ & $0.004(6)$ & 2 & 20.03 & $\mathrm{Ca}$ \\
$M 3$ & -0.5 & -0.5 & 0.5 & $0.024(10)$ & 1 & 23.50 & $\mathrm{Mn}_{0.7}^{*} \mathrm{Ca}_{0.3}$ \\
$M 4$ & 0 & -0.5 & 0.5 & $0.010(9)$ & 1 & 20.01 & $\mathrm{Ca}$ \\
Si1 & $-0.432(6)$ & $-1.201(3)$ & $0.741(3)$ & $0.012(6)$ & 2 & & $\mathrm{Si}$ \\
Si2 & $0.028(7)$ & $-1.173(4)$ & $0.720(4)$ & $0.041(13)$ & 2 & & $\mathrm{Si}$ \\
Si3 & $-0.760(4)$ & $-0.394(3)$ & $-0.060(3)$ & $0.036(9)$ & 2 & & $\mathrm{Si}$ \\
O1 & $-0.692(11)$ & $-0.692(5)$ & $0.473(5)$ & $0.005(2)$ & 2 & & $\mathrm{O}$ \\
O2 & $-0.218(10)$ & $-0.693(6)$ & $0.429(6)$ & $0.02(1)$ & 2 & & $\mathrm{O}$ \\
O3 & $-0.379(12)$ & $-0.400(5)$ & $0.178(5)$ & $0.003(1)$ & 2 & & $\mathrm{O}$ \\
O4 & $-0.524(13)$ & $-0.990(6)$ & $0.731(6)$ & $0.021(2)$ & 2 & & $\mathrm{O}$ \\
O5 & $0.017(15)$ & $-0.963(7)$ & $0.729(7)$ & $0.020(1)$ & 2 & & $\mathrm{O}$ \\
O6 & $-0.864(13)$ & $-0.427(5)$ & $0.175(5)$ & $0.010(8)$ & 2 & & $\mathrm{O}$ \\
O7 & $-0.199(8)$ & $-1.234(6)$ & $0.757(6)$ & $0.046(15)$ & 2 & & $\mathrm{O}$ \\
O8 & $0.034(8)$ & $-0.260(6)$ & $-0.091(6)$ & $0.036(10)$ & 2 & & $\mathrm{O}$ \\
O9 & $-0.583(5)$ & $-0.277(7)$ & $-0.060(6)$ & $0.036(12)$ & 2 & &
\end{tabular}

Примечание. * Mn и $\mathrm{Fe}$, характеризующиеся близкими атомными факторами рассеяния, уточнялись совместно с использованием кривой атомного рассеяния Mn.

Таблица 4

Некоторые межатомные расстояния (§̊) в структуре дальнегорскита

Selected interatomic distances $(\AA)$ in the crystal structure of dalnegorskite

\begin{tabular}{|c|c|c|c|c|c|}
\hline \multirow[t]{7}{*}{ M1 } & $\mathrm{O} 1$ & $2.26(5)$ & Si1 & $\mathrm{O} 1$ & $1.64(4)$ \\
\hline & $\mathrm{O} 3$ & $2.38(6)$ & & $\mathrm{O} 4$ & $1.64(6)$ \\
\hline & $\mathrm{O} 4$ & $2.07(7)$ & & $\mathrm{O} 7$ & $1.71(6)$ \\
\hline & O5 & $2.20(7)$ & & O9 & $1.64(2)$ \\
\hline & O6 & $2.58(7)$ & & Средн. & $<1.66>$ \\
\hline & O8 & $2.36(5)$ & $\mathrm{Si} 2$ & $\mathrm{O} 2$ & $1.52(7)$ \\
\hline & Средн. & $<2.31>$ & & O5 & $1.63(6)$ \\
\hline \multirow[t]{7}{*}{ M2 } & $\mathrm{O} 2$ & $2.46(5)$ & & O7 & $1.72(6)$ \\
\hline & $\mathrm{O} 3$ & $2.28(7)$ & & O8 & $1.65(5)$ \\
\hline & O4 & $2.43(7)$ & & Средн. & $<1.63>$ \\
\hline & O5 & $2.34(8)$ & $\mathrm{Si} 3$ & $\mathrm{O} 3$ & $1.72(4)$ \\
\hline & O6 & $2.63(6)$ & & O6 & $1.69(4)$ \\
\hline & O9 & $2.27(2)$ & & O8 & $1.72(6)$ \\
\hline & Средн. & $<2.40>$ & & O9 & $1.74(2)$ \\
\hline \multirow[t]{4}{*}{ M3 } & $\mathrm{O} 1$ & $2.35(6)$ & & Средн. & $<1.72>$ \\
\hline & $\mathrm{O} 2$ & $2.09(6)$ & & & \\
\hline & $\mathrm{O} 3$ & $2.45(3)$ & & & \\
\hline & Средн. & $<2.30>$ & & & \\
\hline \multirow[t]{5}{*}{ M4 } & $\mathrm{O} 1$ & $2.32(6)$ & & & \\
\hline & $\mathrm{O} 2$ & $2.66(5)$ & & & \\
\hline & O6 & $2.39(3)$ & & & \\
\hline & $\mathrm{O} 7$ & $2.59(4)$ & & & \\
\hline & Средн. & $<2.49>$ & & & \\
\hline
\end{tabular}




\section{ОБСУЖДЕНИЕ РЕЗУЛЬТАТОВ}

Структурный тип бустамита можно рассматривать как производный от структурного архетипа волластонита $\mathrm{Ca}_{3}\left(\mathrm{Si}_{3} \mathrm{O}_{9}\right)$. Топология их кристаллических структур близка: основным элементом являются вытянутые вдоль [100] ленты, образованные кислородными полиэдрами $M \mathrm{O}_{n}$, где видообразующие $M$-катионы $-\mathrm{Ca}, \mathrm{Mn}, \mathrm{Fe}$, и тетраэдрические $\left[\mathrm{Si}_{3} \mathrm{O}_{9}\right]^{\infty}$-цепочки; между собой $M \mathrm{O}_{n}$-полиэдры и цепочки $\left[\mathrm{Si}_{3} \mathrm{O}_{9}\right]$ соединяются по общим кислородным вершинам (рис. 4). Различия между структурами волластонита и бустамита обсуждались в работах (Rapoport, Burnham, 1973; Ohashi, Finger, 1978; Щипалкина и др., 2018). Главное из них заключается в количестве и составе $M$-позиций. Так, в структуре волластонита выделяются три катионные $M$-позиции $(M 1-3)$; все они заполнены практически только атомами Са и характеризуются средними межатомными расстояниями $2.45,2.47$ и $2.39 \AA \AA$ соответственно. $\mathrm{B}$ структуре бустамита катионы Са и $(\mathrm{Mn}, \mathrm{Fe})$ упорядочиваются, что приводит к появлению четвертой независимой $M$-позиции и, соответственно, к искажению катионной $M$-полиэдрической ленты по сравнению с волластонитовой. Как результат этого, в структуре бустамита наблюдается сдвиг тетраэдрических цепочек, примыкающих с двух сторон к катионной ленте, относительно их расположения в структуре волластонита (рис. 5). Сопоставление минералов со структурными типами бустамита и волластонита по основным физическим и кристаллохимическим характеристикам дано в табл. 5.

Одной из главных задач структурного исследования дальнегорскита было установление особенностей распределения катионов между позициями $M$. Основываясь на значениях электронного содержания позиций $\left(\mathrm{e}_{\text {ref }}\right)$, координационных чисел и межатомных расстояний, мы однозначно установили, что в бустамитоподобной структуре дальнегорскита позиции $M 1, M 2$ и $M 4$ характеризуются резким преобладанием Са (они, по сути, могут рассматриваться как занятые только атомами кальция), а позиция $M 3-\mathrm{Mn}^{2+}$-доминантная с примесями $\mathrm{Fe}^{2+}$ и $\mathrm{Ca}$ : при уточнении ее содержания (позиция $M 3$ уточнялась как смешанно-заселенная - $\mathrm{Ca}+\mathrm{Mn}+\mathrm{Fe}$, а для пары «тяжелых» катионов
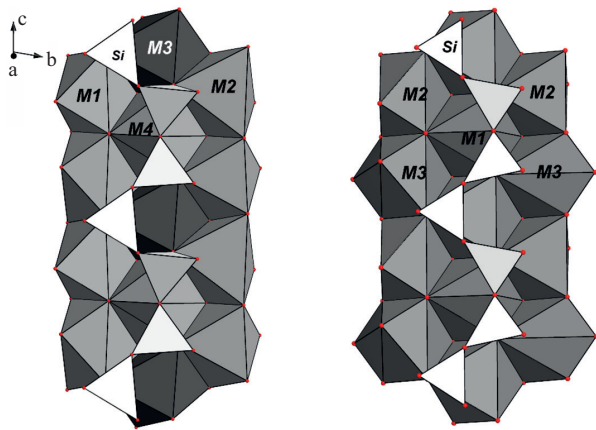

Рис. 4. Фрагменты структур дальнегорскита - представителя структурного типа бустамита (слева) и волластонита-1 $A$ (справа).

Fig. 4. Crystal structures of dalnegorskite, a representative of the bustamite structure type (left figure), and wollastonite-1 $A$ (right figure). $a$

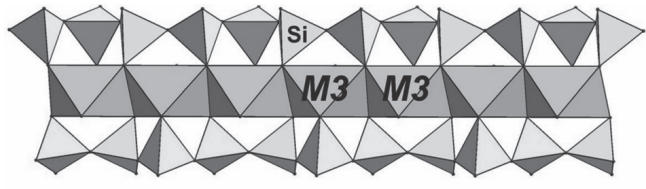

$\sigma$

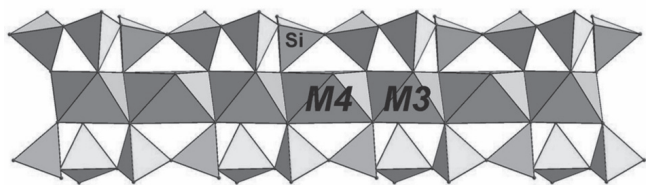

Рис. 5. Характер соединения тетраэдрических цепочек с катионной лентой в структурах $(a)$ - волластонита и (б) - бустамита, по данным работы (Аксенов и др., 2015).

Fig. 5. The arrangement of tetrahedral chains and their joint with cation ribbon in crystal structures of $(a)$ wollastonite and (б) bustamite, after (Aksenov et al., 2015). 


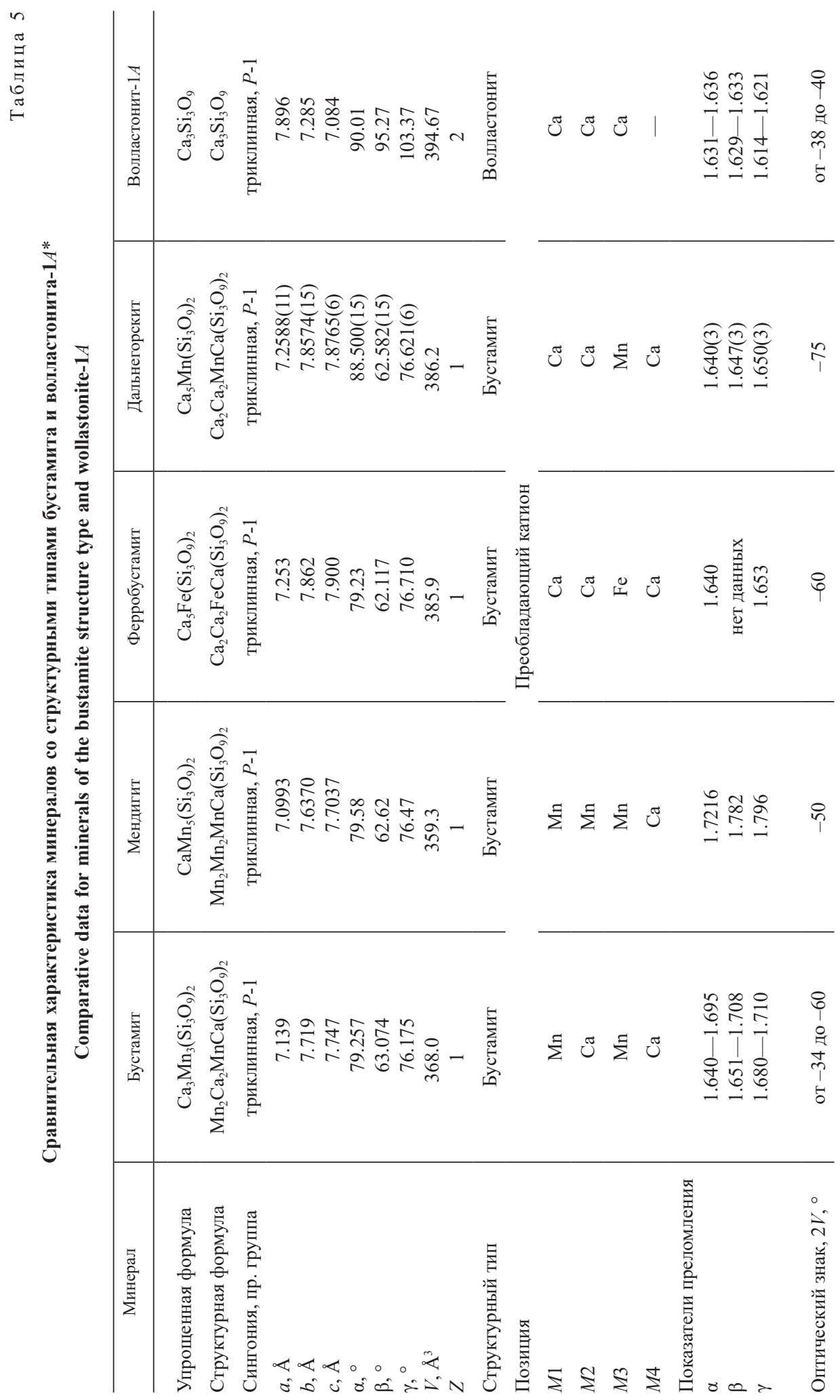




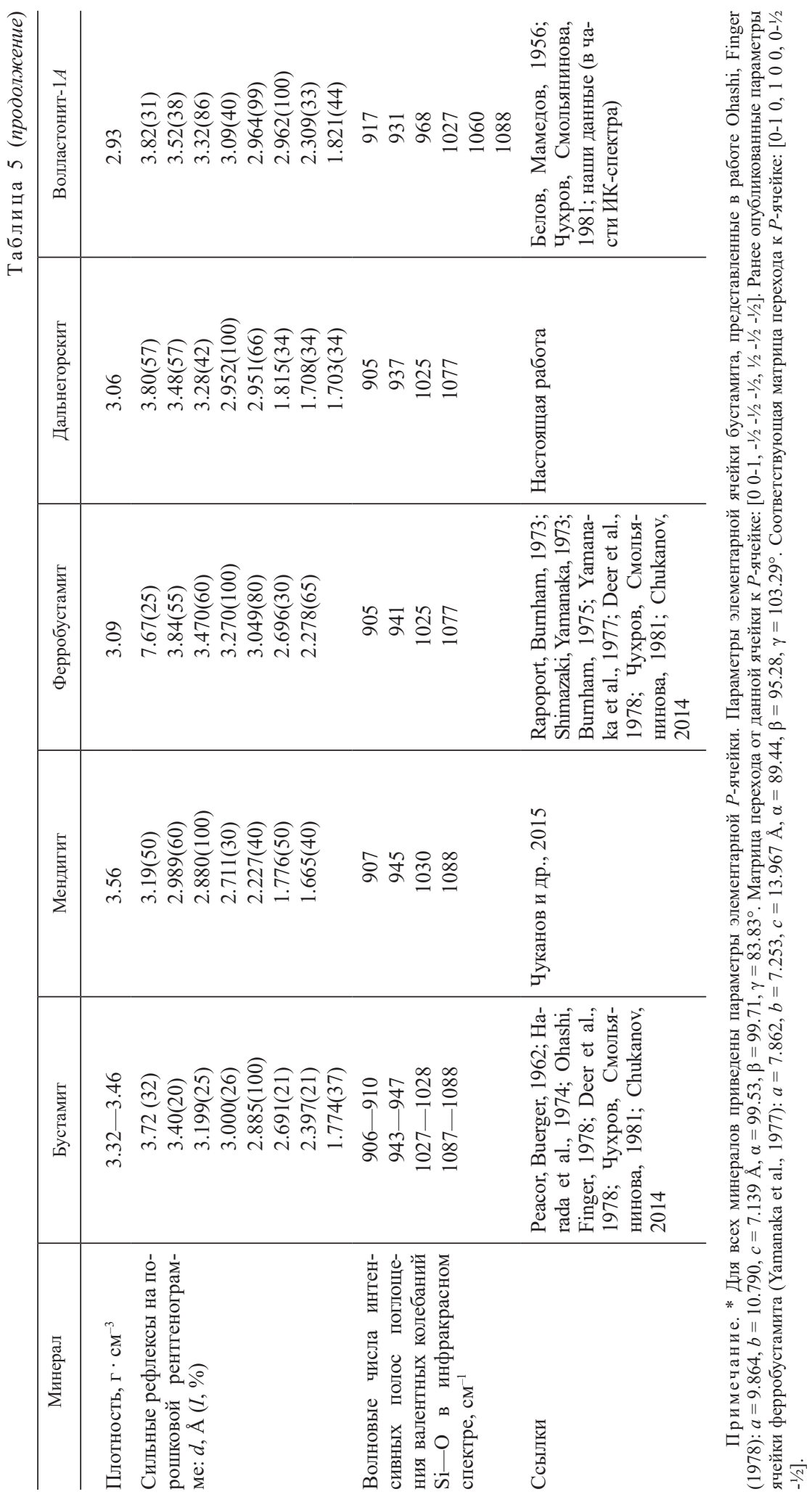




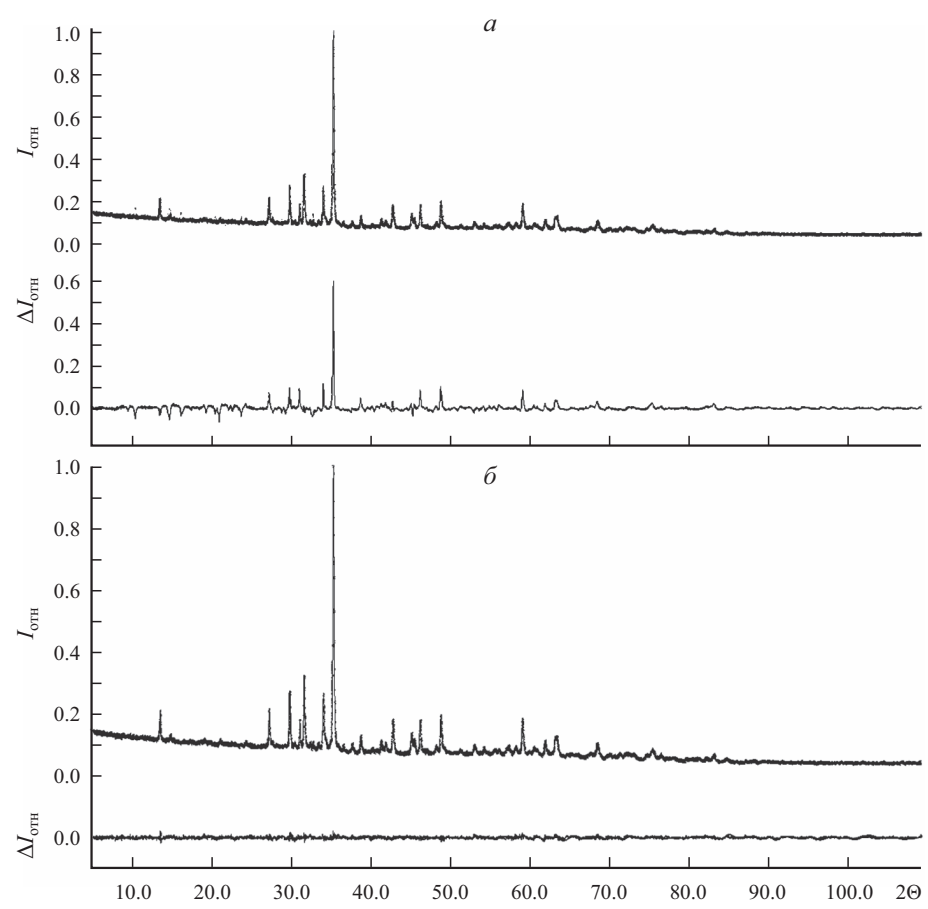

Рис. 6. Результаты уточнения кристаллической структуры дальнегорскита методом Ритвельда с использованием моделей волластонита $(a)$ и бустамита (б). Для каждого рисунка: верхний график экспериментальная порошкограмма дальнегорскита, нижний график - разностная кривая интенсивностей экспериментальной и расчетной рентгенограмм.

Fig. 6. Rietveld refinement plots of dalnegorskite with wollastonite $(a)$ and bustamite (б) structure models. Upper graph is the experimental powder X-ray diffraction pattern of dalnegorskite. The difference between the observed and calculated patterns is shown at lower graph.

$\mathrm{Mn}+\mathrm{Fe}$ была использована кривая рассеяния $\mathrm{Mn})$ - самые низкие значения факторов расходимости получены для состава $\mathrm{Mn}_{0.7} \mathrm{Ca}_{0.3}$. Вывод о преобладании $\mathrm{Mn}$ над $\mathrm{Fe}$ в позиции $M 3$ согласуется с химическим составом изученного образца - голотипа нового минерала.

«Контрольная» попытка уточнения структуры дальнегорскита с использованием модели волластонита показала существенные различия между расчетной рентгенограммой, соответствующей этой модели, и экспериментальной порошковой дифрактограммой минерала (рис. 6). Результат этого уточнения характеризуется и значительно более высокими значениями факторов расходимости: $R_{p}=0.0982, R_{w p}=0.1472, w R_{2}=0.1040$.

Таким образом, два независимых метода - рентгеноструктурный анализ и инфракрасная спектроскопия - однозначно подтвердили принадлежность дальнегорскита к структурному типу бустамита, а не волластонита. Кристаллохимическая формула конечного члена нового минерала ${ }^{M 1} \mathrm{Ca}_{2}{ }^{M 2} \mathrm{Ca}_{2}{ }^{M 3} \mathrm{Mn}^{M 4} \mathrm{Ca}\left(\mathrm{Si}_{3} \mathrm{O}_{9}\right)_{2}$.

Интересно отметить, что пироксеноид, кристаллохимически близкий к голотипу дальнегорскита, был описан как «Са-бустамит» в работе (Ohashi, Finger, 1978) на марганцевом месторождении Хидзикузу (Hijikuzu) в префектуре Ивате на острове Хонсю в Японии. Его химический состав: СаО 36.4, $\mathrm{MgO}$ 0.6, $\mathrm{MnO}$ 7.2, $\mathrm{FeO} 4.4, \mathrm{SiO}_{2}$ 50.5, сумма 99.1 мас. \%, а эмпирическая 




Рис. 7. Соотношения главных $M$-катионов в: $\square$ - дальнегорските из Дальнегорского месторождения (данная работа) и месторождения Хидзикузу, Япония (Ohashi, Finger, 1978), и ○ - ферробустамите (Rapoport, Burnham, 1973; Shimazaki, Yamanaka, 1973; Burnham, 1975; Yamanaka et al., 1977; Щипалкина и др., 2018). Звездочками обозначены составы гипотетических конечных членов дальнегорскита (Dln) и ферробустамита (Fbst).

Fig. 7. Ratios of major $M$ cations in: $\square-$ dalnegorskite from Dalnegorsk (this work) and Hijikuzu, Japan (Ohashi, Finger, 1978), and ○ - ferrobustamite (Rapoport, Burnham, 1973; Shimazaki, Yamanaka, 1973; Burnham, 1975; Yamanaka et al., 1977; Shchipalkina et al., 2018). Stars indicate the idealized, end-member compositions of dalnegorskite (Dln) and ferrobustamite (Fbst).

формула - $\mathrm{Ca}_{4.61} \mathrm{Mn}_{0.73} \mathrm{Fe}_{0.44} \mathrm{Mg}_{0.11} \mathrm{Si}_{6.05} \mathrm{O}_{18}$. По результатам расшифровки его структуры методом монокристального рентгеноструктурного анализа выведена упрощенная кристаллохимическая формула ${ }^{M 1} \mathrm{Ca}_{2}{ }^{M 2} \mathrm{Ca}_{2}{ }^{M 3} \mathrm{Mn}^{M 4} \mathrm{Ca}\left(\mathrm{Si}_{3} \mathrm{O}_{9}\right)_{2}$ (Ohashi, Finger, 1978), которая соответствует дальнегорскиту. Таким образом, этот минерал на сегодня достоверно известен из двух месторождений.

В скарнах Дальнегорского боросиликатного месторождения распространены промежуточные члены ряда дальнегорскит-ферробустамит (табл. 1, рис. 7). Соотношение $\mathrm{Mn}$ и $\mathrm{Fe}$ в них варьирует от $\left(\mathrm{Mn}_{0.78} \mathrm{Fe}_{0.46}\right)$ до $\left(\mathrm{Fe}_{0.59} \mathrm{Mn}_{0.51}\right)$. Вхождение катионов с разными ионными радиусами $\left[\mathrm{Ca}-1.00, \mathrm{Mn}^{2+}-0.83\right.$, $\mathrm{Fe}^{2+}-0.78 \AA$ для октаэдрической координации (Shannon, Prewitt, 1970)] в одни и те же структурные позиции (в первую очередь M3) в соседних элементарных ячейках или же в неких более крупных блоках структуры могло привести к гетерометрии кристаллической решетки в разных частях кристалла и, соответственно, обусловить расщепление индивидов этих минералов, вплоть до образования сферокристаллов. Подобные явления подробно описаны в работах (Пунин, 1981; Fernandez-Diaz et al., 2006).

Работа выполнена при поддержке РФФИ, проект № 18-05-00332. ИК-спектроскопические исследования выполнены по теме Государственного задания, № государственной регистрации 0089-2016-0001.

\section{Список литературы}

Аксенов С. М., Щипалкина Н. В., Расиветаева Р. К., Русаков В. С., Пеков И. В., Чуканов H. B., Япаскурm B. O. Высокожелезистый бустамит из Брокен-Хилла, Австралия: кристаллическая структура и особенности катионного упорядочения // Кристаллография. 2015. Ч. 60. № 3. C. $385-390$.

Белов Н. В., Мамедов К. С. Кристаллическая структура минералов группы волластонита. Кристаллическая структура ксонотлита // ЗВМО. 1956. № 1. С. 13-38.

Казаченко В. T., Перевозникова E. В., Нарнов Г. А. Акцессорная минерализация в скарнах Дальнегорского рудного района (Сихотэ-Алинь) // ЗРМО. 2012. № 4. С. $73-96$.

Куршакова Л. Д. Физико-химические условия образования боросиликатных месторождений. М.: Наука, 1976. 273 с.

Мельницкая Е. Ф. Мn-Fе волластонит и его преобразования // ЗВМО. 1967. № 3. С. 297-305.

Пунин Ю. О. Расщепление кристаллов // ЗВМО. 1981. № 6. С. 666-686.

Чуканов Н. В., Аксёнов С. М., Расиветаева Р. К., Ван К. В., Белаковский Д. И., Пеков И. В., Гуржсий В. В., Шюллер В., Тернес Б. Мендигит, $\mathrm{Mn}_{2} \mathrm{Mn}_{2} \mathrm{MnCa}\left(\mathrm{Si}_{3} \mathrm{O}_{9}\right)_{2}$, новый минеральный вид 
группы бустамита из вулканического района Айфель Айфеля, Германия // ЗРМО. 2015. № 2. C. $48-60$.

Чухров Н. В., Смольянинова Н. Н. (ред.) Минералы. Справочник. М.: Наука. 1981. Т. 3. В. 2.614 с.

Щипалкина Н. В., Кононов О. В., Пеков И. В., Кочлякова Н. Н., Бритвин С. Н. Волластонит и ферробустамит Тырныаузского рудного поля (Северный Кавказ): химический состав, взаимоотношения и минералого-технологический аспект // Новые данные о минералах. 2018. Т. 52. № 2. C. $43-50$.

\section{References}

Aksenov S. M., Shchipalkina N. V., Rastsvetaeva R. K., Pekov I. V., Chukanov N. V., Yapaskurt $V$. $O$. Iron-rich bustamite from broken Hill, Australia: The crystal structure and cation-ordering Features. Cryst. Rep. 2015. Vol. 60. N 3. P. 340-345.

Belov N. V., Mamedov K. S. Crystal structures of wollastonite-group minerals. The crystal structure of xonotlite. Zapiski RMO (Proc. Russian Miner. Soc.). 1956. Vol. 85. N 1. P. 13-38 (in Russian).

Burnham C. W. Ferrobustamite: the crystal structures of two Ca, Fe bustamite-type pyroxenoids: correction. Z. Krist. 1975. Vol. 142. P. $450-452$.

Chukanov N. V. Infrared Spectra of Mineral Species: Extended Library. Springer-Verlag GmbH, Dordrecht. 2014. $1716 \mathrm{p}$.

Chukanov N. V., Aksenov S. M., Rastsvetaeva R. K., Van K. V., Belakovskiy D. I., Pekov I. V., Gurzhiy $V$. $V$., Schüller $W$., Ternes $B$. Mendigite, $\mathrm{Mn}_{2} \mathrm{Mn}_{2} \mathrm{MnCa}\left(\mathrm{Si}_{3} \mathrm{O}_{9}\right)_{2}$, a new mineral species from the Eifel volcanic region, Germany. Zapiski RMO (Proc. Russian Miner. Soc.). 2015. N 2. C. 48 60 (in Russian, English translation: Geol. Ore Deposits. 2015. Vol. 57. N 8. P. 721-731).

Chukhrov F. V., Smolianinova N. N. (eds.) Minerals. Reference Book. Moscow: Nauka, 1981. Vol. 3. N 2. 614 p. (in Russian).

Deer W. A., Howie R. A., Zussman J. Rock-Forming Minerals. Volume 2A. Single-Chain Silicates. London: Longman, 1978.

Fernandez-Diaz L., Astilleros J. M., Pina C. M. The morphology of calcite crystals grown in a porous medium doped with divalent cations. Chem. Geol. 2006. Vol. 225. P. 314-321.

Harada K., Sekino H., Nagashima K., Watanabe T., Momoi H. High-iron bustamite and fluorapatite from the Broken Hill mine, New South Wales, Australia. Miner. Mag. 1974. Vol. 39. P. 601—604. Kazachenko V. T., Perevoznikova E. V., Narnov G. A. Accessory mineralization in skarns of Dalnegorsk ore district (Sikhote-Alin). Zapiski RMO (Proc. Russian Miner. Soc.). 2012. N 4. P. 7396 (in Russian).

Kurshakova L. D. Physical-chemical conditions of origin of boron-silicate deposits. Moscow: Nauka, 1976. 273 p. (in Russian).

Moroshkin V.V., Frishman N. I. Dalnegorsk: notes on mineralogy. Miner. Alm. 2001. N 4. 136 p. Melnitskaya E. F. Manganese-iron wollastonite and its alteration. Zapiski RMO (Proc. Russian Miner. Soc.). 1967. Vol. 96. N 3. P. 297-305 (in Russian).

Ohashi Y., Finger L. W. The role of octahedral cations in pyroxenoid crystal chemistry. I. Bustamite, wollastonite, and pectolite-schizolite-serandite series. Amer. Miner. 1978. Vol. 63. P. 274-288. Petřiček V., Duŝek M., Palatinus L. Crystallographic Computing System JANA2006: General features. Z. Krist. 2014. Vol. 229. N 5. P. 345-352.

Peacor D. R., Buerger M. J. Determination and refinement of the crystal structure of bustamite, $\mathrm{CaMnSi}_{2} \mathrm{O}_{6}$. Z. Krist. 1962. Vol. 117. P. $331-343$.

Punin Yu. O. Crystal splitting. Zapiski RMO (Proc. Russian Miner. Soc.). 1981. Vol. 110. N 6. P. 666-686 (in Russian).

Rapoport P. A., Burnham C. W. Ferrobustamite: the crystal structures of two Ca,Fe bustamitetype pyroxenoids. Z. Krist. 1973. Vol. 1386. P. 419-438.

Shchipalkina N. V., Kononov O. V., Pekov I. V., Koshlyakova N. N., Britvin S. N. Wollastonite and ferrobustamite of the Tyrnyauz ore field (North Caucasus): chemical composition, relations and mineralogical-technological aspect. New Data Miner. 2018. Vol. 52. N 2. P. $43-50$ (in Russian).

Shannon R. D., Prewitt C. T. Revised values of effective ionic radii. Acta Cryst. 1970. Vol. B26, N 7. P. $1046-1048$.

Shimazaki H., Yamanaka T. Iron-wollastonite from skarns and its stability relation in the $\mathrm{CaSiO}_{3}-\mathrm{CaFeSi}_{2} \mathrm{O}_{6}$ join. Geochem. J. 1973. Vol. 7. P. 67-79.

Yamanaka T., Sadanaga R., Takéuchi Y. Structural variation in the ferrobustamite solid solution. Amer. Miner. 1977. Vol. 62. P. 1216-1224. 